\title{
DEFENSIVE ADAPTATIONS OF SOME NEOTROPICAL LONG-HORNED BEETLES (COLEOPTERA, CERAMBYCIDAE): ANTENNAL SPINES, TERGIVERSATION, AND DOUBLE MIMICRY
}

\author{
By Robert E. Silberglied And Annette Aiello \\ *Smithsonian Tropical Research Institute, \\ P.O. Box 2072, Balboa, Panama Canal Zone
}

The large and diverse beetle family Cerambycidae is well-represented in the neotropical region, and contains numerous examples of species with interesting and often bizarre defensive adaptations. These include examples of cryptic coloration, defensive use of mandibles, body spines, death feigning, unpalatability coupled with aposematism, and Müllerian and Batesian mimicry. Linsley (1959a, 1959b, 1961) has reviewed the subject of structural and behavioral defense adaptations, protective coloration and mimicry in this family (see also Chemsak and Linsley, 1970, Funke, 1957). We here report field observations on three new and unusual cases of defensive adaptations of these beetles, made during 1976 on Barro Colorado Island, Panama Canal Zone.

\section{Antennal spines.}

Both sexes of Hammaticherus batus (Linnaeus) have elongate recurved spines on segments 3-6 of their antennae (Figure 1A). These downward-projecting lateral extensions, located at the distal end of the segments, are sharply-pointed, with the inner edge of each point continuing basally as a concave, knife-like ridge (Figure 1B). Other members of the genus have similar spines, and, since their distribution among the basal segments differs from species to species, they have been employed as taxonomic characters within the genus. Such spines as occur on the body and appendages of cerambycids and other insects have often been assumed, in general, to be defensive in function (Edmunds, 1974, Linsley, 1959a, 1961), but there are few accounts of the ways in which spines are actually employed.

Upon being grasped transversely with the fingers, Hammaticherus batus extends its head slightly, flailing the antennae back-

\footnotetext{
*Present address: Department of Biology, Harvard University, Cambridge,
} Massachusetts, U.S.A. 02138 




Figure 1. Hammaticherus batus: antennal defense. A, note antennal spines on segments 3-6; B, spine of segment 3, enlarged; C, spine in use: the beetle pulls its head downward, setting the spines in the skin and drawing blood (arrow) from the forefinger. [scale, $\mathrm{IC}=1 \mathrm{~cm}$.] 
wards and downwards, so that the pointed processes come into contact with the skin. The head is then withdrawn tightly against the prothorax and rotated from a prognathous to a hypognathous position, deeply setting the antennal hooks. They are sharp enough to penetrate the skin, causing surprise, sudden pain and occasionally drawing blood (Figure 1C). Presumably a predator that grabbed one of these beetles would be similarly surprised, possibly injured, and might immediately drop the intended prey. The hoods withdraw easily from the skin once the body of the beetle has been released.

The antennae of cerambycids are the longest known in the Coleoptera, both in an absolute sense and in relation to body size. Unlike the antennae of many other beetles, they are fully exposed and are often too long to be concealed in prothoracic grooves or other receptacles. Conceivably the use of antennae in defensive behavior is most likely to occur in insects the antennae of which are so large or so long that the alternative of concealment is no longer an option. We know of no other instance in which the antennae of an insect are used defensively.

\section{Tergiversation.}

When first seen, Oreodera glauca (Linnaeus) (Figure 2) appears to be a light-colored, wedge-shaped insect with two conspicuous legs directed "anteriorly." The banded antennae appear to arise from a broad, distinct "head" bearing short horns. The entire effect is an illusion; the real head is located at the other end of the body.

This illusion is achieved by a combination of color pattern and resting posture. The false "head" consists of the apices of the elytra, which are separated from the basal regions by a transverse, darkly pigmented line. False constrictions in the "cervical" region and elsewhere are produced by dark lateral markings. The true pronotum and head are somewhat darker in color and not easily recognized as such. The most important postural adaptation is the positioning of the antennae, which serve two different functions. At the true head, the enlarged antennal bases cover the compound eyes, which otherwise would be visible and would destroy the reversed effect. The antennae are held closely along the sides of the body, and emerge from beneath the elytral apices, where they appear to arise from the false head. Finally, the third 


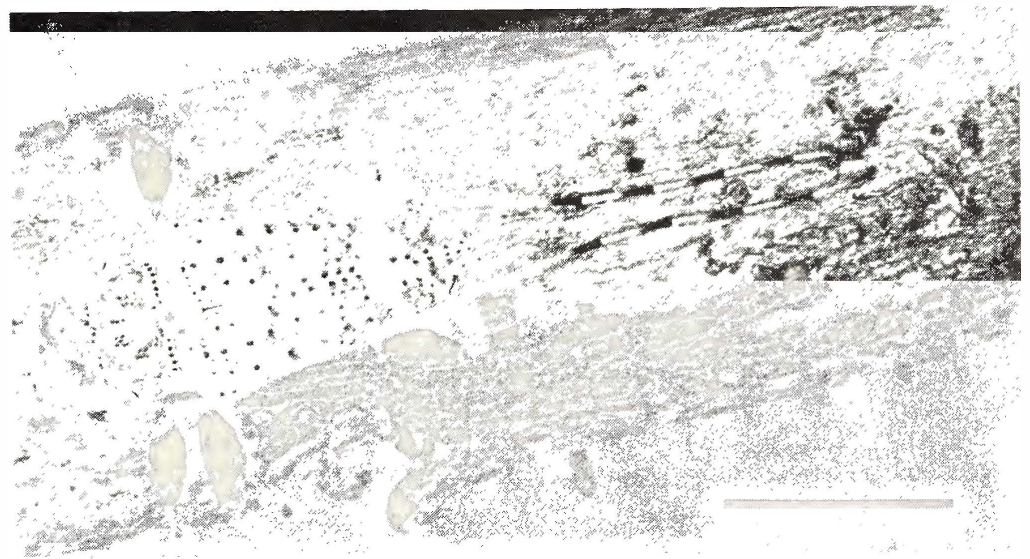

Figure 2. Oreodera glauca: tergiversation. The insect appears headed toward the right, but in fact it is oriented in the opposite direction. [scale $=1 \mathrm{~cm}$.]

pair of legs is directed in such a way as to appear to be a first pair, an effect enhanced by the first and second pairs of legs which are grouped together at the true pronotum. The total effect is of a rather nondescript insect headed in a direction that is the reverse of its true orientation.

Predators are well-known to attack insects at the head end, often using the eyes of the prey for orientation. False eyespots and other patterns employed by prey to redirect the attack to less vital regions afford them the opportunity to escape, and are common in many insects, especially Lepidoptera. Their adaptive significance has been experimentally confirmed on several occasions, most notably by Blest (1957). Such eyespots, and other features so employed, have been aptly termed "deflection marks." We here employ the term "tergiversation" (literally, "to turn the back") to refer to the complete illusion of reversed orientation. Tergiversation is variously defined as "the desertion of a direction or of a cause, . . . an equivocation, . . . a subterfuge, . . . an evasion, ... a turning of the back, as in flight." We feel that tergiversation is a more general term, which includes the behavioral components as well as pattern elements, and emphasizes the complete effect, rather than the parts (such as deflection marks) that produce it. Incidentally, Oreodera glauca has no distinctive eyespots or deflection marks at all! 


\section{Double mimicry.}

The third and final example of a defensive adaptation involves mimicry. Mimicry is highly developed in the Cerambycidae (e.g., Gahan, 1913; Shelford, 1902, 1916), and has been well-reviewed by Linsley (1959a, 1959b, 1961). We here draw attention to Acyphoderes sexualis Linsley, a cerambycid that appears to mimic two different groups of stinging Hymenoptera, wasps and ants.

At rest, and especially when walking about, Acyphoderes sexualis (Figure 3A-3C) bears a striking resemblance to a large ponerine ant, such as Paraponera clavata. The resemblance is produced by the following adaptations: The antennae are short (for a cerambycid) and are moved in an antlike manner. The elytra are abbreviated and swollen at the base, enlarging the apparent thorax. The hindwings are heavily infuscated and are not folded beneath the elytra at rest, but rather are clipped in place by the elytra on the abdominal dorsum, where they are tightly twisted along the petiolate basal part, and expanded apically to produce the effect of a large dark gaster. The beetle's behavior convincingly adds to the resemblance of a ponerine ant. Upon being grasped, the beetle makes stinging movements with the abdomen. Since the abdominal apex is quite hard and sharp, the sensation of an impending sting is quite effective. Moreover, like many ponerine ants, the beetle stridulates when handled.

Upon taking flight, the appearance of the beetle changes suddenly to that of a wasp (Figure 3D-3F). For a moment the dark hindwings are raised at an angle to the body, and the "petiole" and "gaster" are slightly reduced in apparent size. The petiole now appears very thin, and the gaster more bulbous. This appearance is retained during flight, when the wasplike effect is enhanced by the hanging legs. The "wasp" is seen momentarily upon landing, just before the hindwings are again clipped in place by the elytra and the "ant" suddenly reappears.

There are many different wasp species that could potentially serve as models, especially the numerous and aggressive dark polybiines, such as Polybia rejecta. The beetle is therefore presumed to be a "group mimic" of large, dark ponerine ants and medium-sized, dark vespoid wasps, two of the most abundant, conspicuous, aggressive, and best-defended insects in neotropical rain forests, including Barro Colorado Island. We have no information as to the palatability of the beetle. 

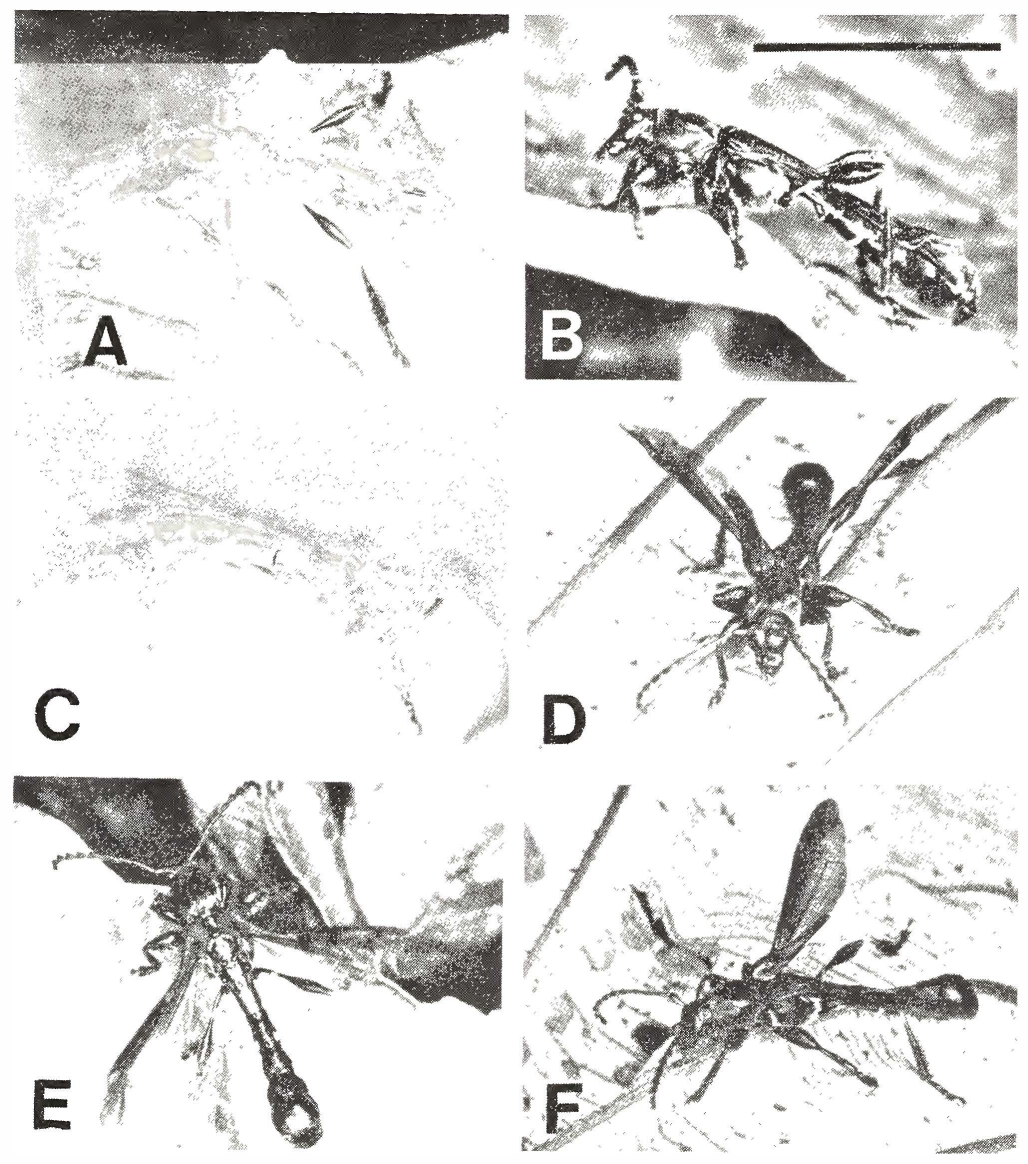

Figure 3. Acyphoderes sexualis: double mimicry. A-C, ant mimicry; D-F, wasp mimicry. [scale, $3 \mathrm{~B}=1 \mathrm{~cm}$.]

Acyphoderes sexualis is one of the most effective mimetic insects we have ever encountered. When we offered the living, hand-held specimen to numerous visitors to the research station, the effect, without exception, was initial sudden withdrawal and surprise at our handling of it. We suggest the term "double mimicry" for cases in which a single insect resembles two distinct models at different times. This is not the same as "dual mimicry," in which the two sexes of a species mimic different models, a situation 
that also occurs in the remarkable beetle family Cerambycidae (ref. in Linsley, 1959b).

We thank E. G. Linsley and John A Chemsak for determination of the beetles, the Smithsonian Tropical Research Institute for use of facilities, and Nancy Hinnebusch for typing the manuscript. Specimens have been deposited in the National Museum of Natural History, Smithsonian Institution.

\section{REFERENCES}

Blest, A. D.

1957. The function of eyespot patterns in the Lepidoptera. Behavior, 11: 209-256.

Chemsak, J. A. and Linsley, E. G.

1970. Death-feigning among North American Cerambycidae (Coleoptera). Pan-Pacific Entomol., 46: 305-307.

EdMunds, M.

1974. Defense in Animals. Longman, Essex, England. xvii +357 p.

FUNKE, W.

1957. Zur Biologie und Ethologie einheimischer Lamiinen (Cerambycidae, Coleoptera). Zool. Jahrb., 85: 73-176.

Gahan, C. J.

[1913]. Mimicry in Coleoptera. Proc. South London Entomol. and Natur. Hist. Soc., 1912-1913: 28-38, + pl. 8-10.

LINSLEY, E. G.

1959a. Ecology of Cerambycidae. Ann. Rev. Entomol., 4: 99-138.

1959b. Mimetic form and coloration in the Cerambycidae (Coleoptera). Ann. Entomol. Soc. America, 52: 125-131.

1961. The Cerambycidae of North America. Part I. Introduction. Univ. California Publ. Entomol., 135 p.

SHELFord, R. [W. C.]

1902. Observations on some mimetic insects and spiders from Borneo and

[1903]. Singapore, with appendices containing descriptions of new species by R. Shelford, K. Jordan, C. J. Gahan, the Rev. H. S. Gorham, and A. Senna. Proc. Zool. Soc. London, 1902, 2: 230-284, + pl. 19-23.

Shelford, R. W. C.

1916. A naturalist in Borneo, edited with a biographical introduction by Edward B. Poulton. T. Fisher Unwin Ltd., London. xxvii +331 p. 


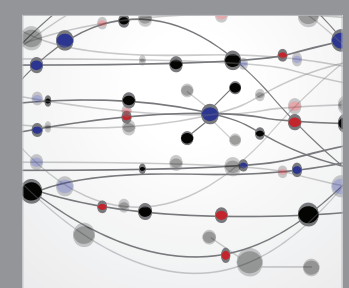

The Scientific World Journal
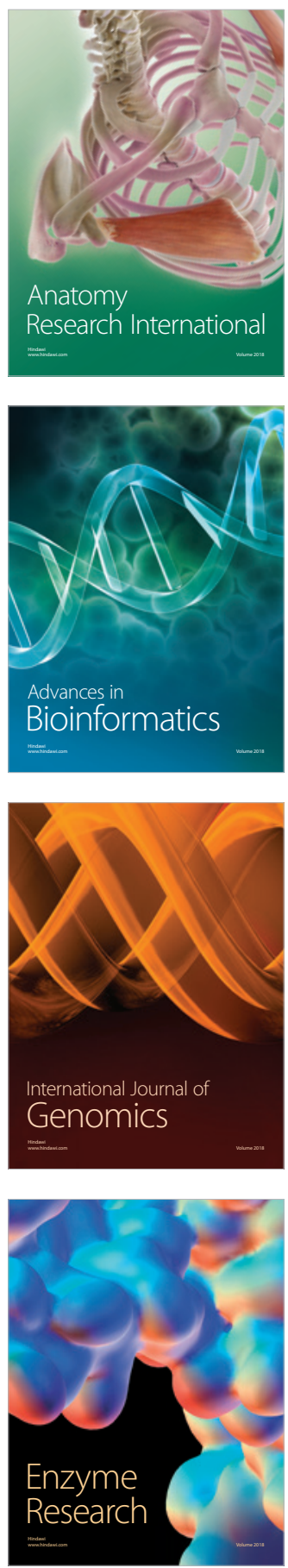
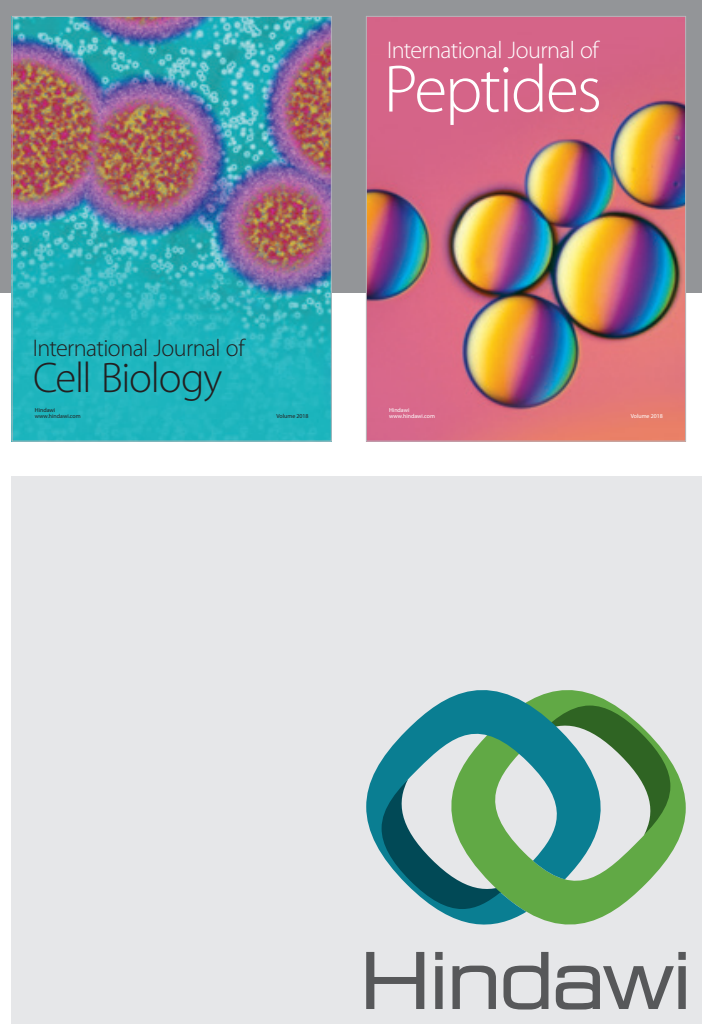

Submit your manuscripts at

www.hindawi.com
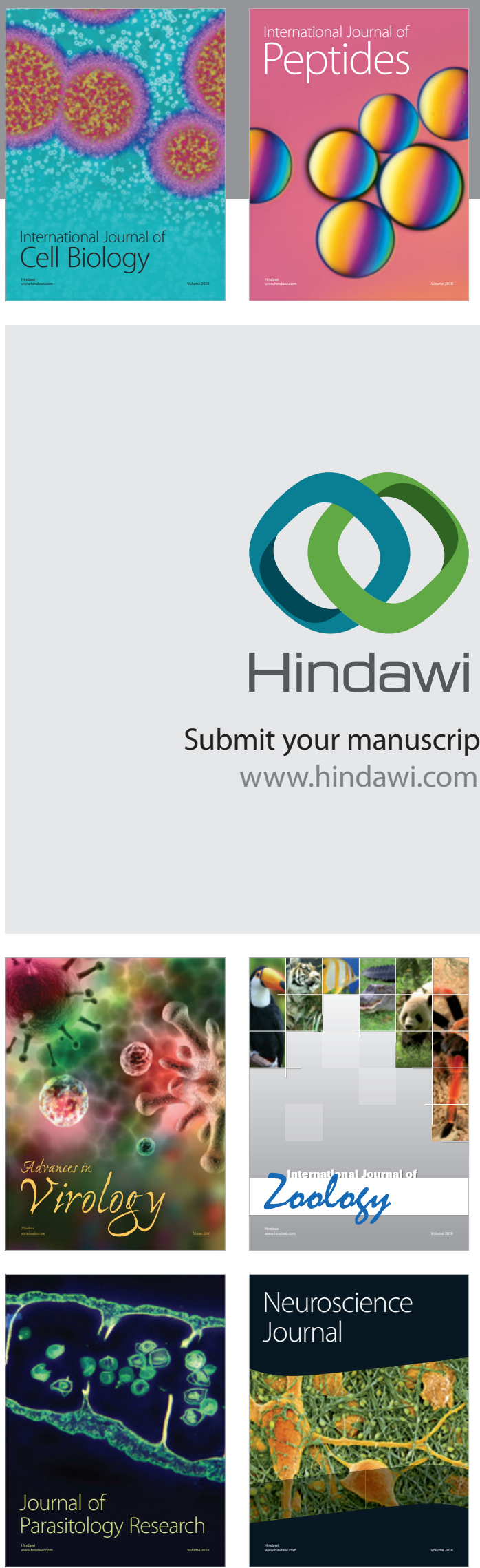
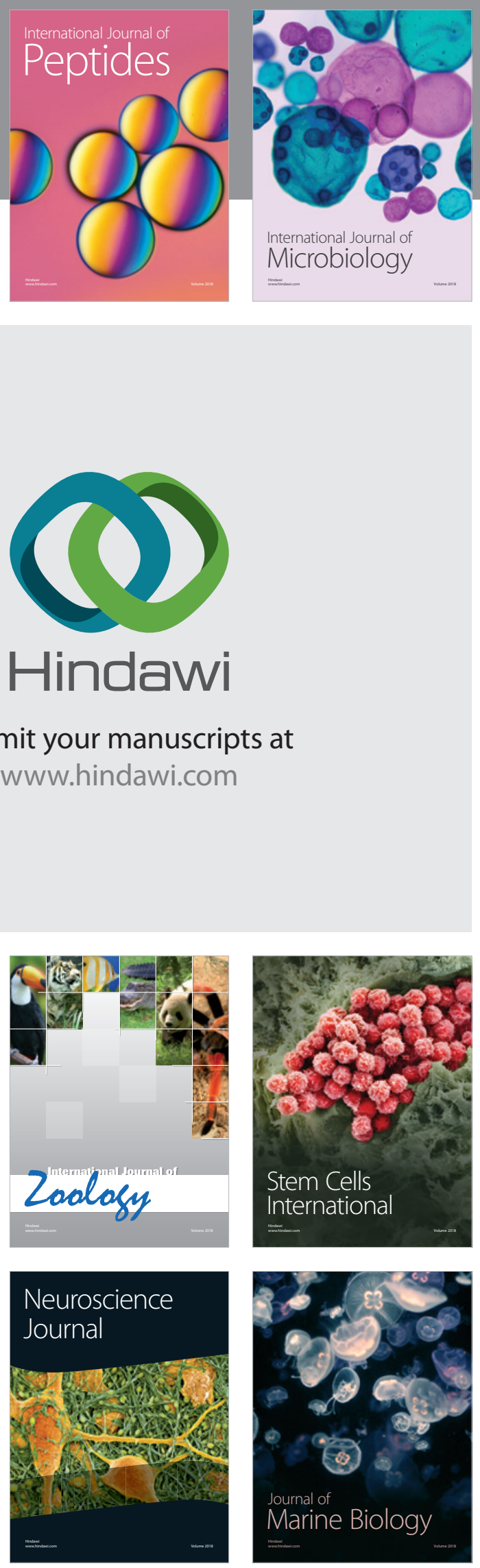
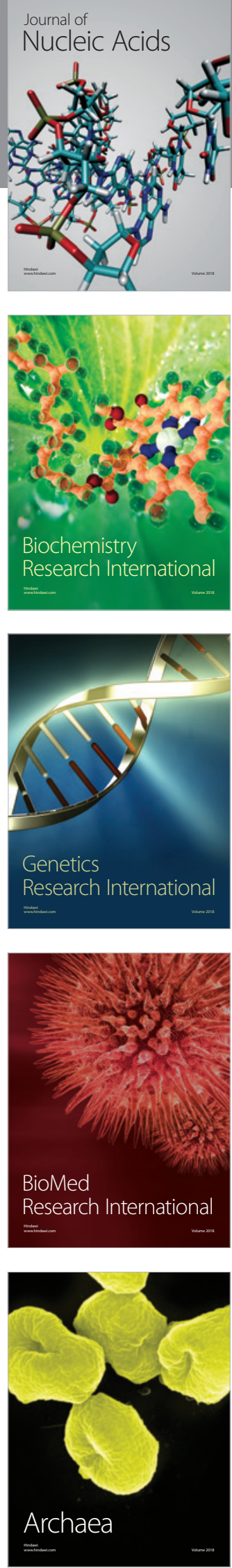